\title{
"humanidades
}

Revista Humanidades

ISSN: 2215-3934

humanidades@ucr.ac.cr

Universidad de Costa Rica

Costa Rica

\section{El lugar de la Amazonia en los libros de texto de historia en Brasil: sobre historia, narrativa y enseñanza}

\author{
Cavalcanti, Erinaldo \\ Revista Humanidades, vol. 12, núm. 1, e49299, 2022 \\ Universidad de Costa Rica, Costa Rica \\ Disponible en: https://www.redalyc.org/articulo.oa? $\mathrm{id}=498068490014$ \\ DOI: https://doi.org/10.15517/h.v12i1.49299
}

El lugar de la Amazonia en los libros de texto de historia en Brasil: sobre historia, narrativa y enseñanza ${ }^{1}$

\section{(c) (1) $\Theta \Theta$}

Esta obra está bajo una Licencia Creative Commons Atribución-NoComercial-SinDerivar 3.0 Internacional. 


\section{El lugar de la Amazonia en los libros de texto de historia en Brasil: sobre historia, narrativa y enseñanza ${ }^{1}$}

The place of the Amazon in history textbooks in Brazil: about history, narrative and teaching

Erinaldo Cavalcanti

Universidad Federal de Pará, Belén, Brasil

ericontadordehistorias@gmail.com

(iD https://orcid.org/0000-0002-9912-5713

\author{
DOI: https://doi.org/10.15517/h.v12i1.49299 \\ Redalyc: https://www.redalyc.org/articulo.oa? \\ $\mathrm{id}=498068490014$
}

\section{Resumen:}

El artículo propone analizar cómo se representa la Amazonia brasileña en los libros de texto de historia de los últimos cursos de educación primaria, aprobados por el Programa Nacional de Libros de Texto (PNLD) 2020. Con este fin, se seleccionaron 40 libros publicados en 10 colecciones que compiten como opción para la adquisición de los libros de texto que serán utilizados por miles de estudiantes y profesores que trabajan en el sistema público de enseñanza. Los análisis muestran una narrativa que presenta a la Amazonia habitada por personas sin nombre, representada de manera generalizada y asociada a los tiempos de la aparición de los primeros habitantes en las Américas y a la época de la colonización portuguesa.

Palabras ClaVE: Enseñanza de la historia, libro de texto, narrativa, Amazonia.

\section{Abstract:}

The article proposes to analyze how the Brazilian Amazon is represented in the history textbooks of the final years of elementary school, approved in the National Textbook Program (PNLD) 2020. For this, we selected 40 books published in 10 collections that offer their products and compete as options for the acquisition of textbooks that will be used by thousands of students, teachers and teachers working in the public education network. The analyzes show a narrative that represents the Amazon inhabited by people without a name, represented in a generalized way and associated with the time of the appearance of the first inhabitants in the Americas and the time of Portuguese colonization.

KEYWORDS: History teaching, textbook, narrative, Amazon.

\section{INTRODUCCIÓN}

Este texto es el resultado del proyecto de investigación titulado Enseñanza de la Historia, libro de texto y formación docente: entre prácticas y representaciones. Dicho proyecto se desarrolló en el laboratorio y grupo de investigación Interpretación del Tiempo: enseñanza, memoria, narrativa y política (iTemnpo). Este centro está vinculado a la línea de investigación Enseñanza de Historia, narrativas y documentos del Programa de Posgrado en Historia de la Universidad Federal del Sur y Sudeste de Pará (Brasil). A partir de 2019, el estudio llevado a cabo en nuestro laboratorio se incorporó al proyecto de investigación Las Ciencias Sociales en lo ámbito iberoamericano: análisis de libros de texto. Dicho proyecto consiste en una investigación liderada por la Universidad de Zaragoza (España) con la colaboración del Centro Internacional de la Cultura Escolar (CEINCE) Berlanga de Duero-Soria.

De tal forma, fue parte de los objetivos de la investigación comprender cómo está representada la región amazónica en los libros de texto de Historia de la educación primaria. ${ }^{1}$ Este artículo, por lo tanto, amplía el análisis sobre las representaciones construidas en 40 libros de texto de Historia de la Educación Básica, los cuales fueron publicados en 2018 por 10 editoras por medio del Programa Nacional de Libros de Texto (PNLD). El análisis muestra que la Amazonia se representa como un lugar lejano, un espacio sin personas y cuyas historias se asocian con la aparición del hombre en el continente americano y la llegada de los europeos a América. 
Para entender cómo se presenta la Amazonia en los libros de texto, primero es necesario explicarle al público no nativo algunas características del proceso de producción de los textos didácticos en Brasil. Lo anterior quiere decir que para cualquier análisis del libro de texto de la Educación Básica (enseñanza primaria y secundaria), en Brasil, es necesario obtener algunas informaciones preliminares sobre el proceso de construcción que regula toda la fabricación de esos materiales. Actualmente, en Brasil, los libros de texto para las escuelas públicas de la Educación Básica son producidos a partir de una política pública de estado. Es decir, el Estado Brasileño es el responsable del proceso, desde la inscripción de las obras a los edítales públicos hasta la evaluación del material, la distribución en las escuelas para la selección de los profesores y la distribución a los estudiantes. Todo eso ocurre en un largo periodo de aproximadamente 2 años. A su vez, ese conjunto de procedimientos con reglas y etapas es coordinado por el PNLD.

Hay un conjunto de criterios obligatorios para todos las editoriales que desean inscribirse en el PNLD. Algunas de las principales normas definen que los materiales inscritos no pueden presentar cualquier identificación de los autores y de las editoras para mantener el anonimato en el proceso de evaluación. Hasta el golpe político de 2016, las universidades federales eran elegidas por el Ministerio de la Educación (MEC) para formar un equipo de profesores/investigadores especialistas en cada área de conocimiento. En los últimos Edictos Públicos de PNLD, también fueron incorporados a los equipos, profesores de la enseñanza primaria y secundaria. El proceso de evaluación involucra muchas dimensiones como, por ejemplo: las especificidades cognitivas para cada rango de edad de los estudiantes, las singularidades del proceso de enseñanza, aprendizaje y la evaluación.

En Brasil hay una amplia bibliografía especializada sobre los temas que involucran las políticas públicas de producción de libro de texto. Una obra considerada referencia es Livro didático de História: entre políticas e narrativas (2017), producido y organizado por Helenice Rocha, Luiz Reznik, y Marcelo Magalhães. El libro brinda un rico panorama de los principales temas de análisis sobre el libro de texto.

La profesora e investigadora Flávia Caimi (2018) ha hecho relevantes contribuciones sobre el tema. En este sentido, ella muestra la importancia del PNLD como una política de Estado para una producción de calidad de los libros de texto. La profesora resalta que el programa presenta una trayectoria construida de forma consistente hace más de 3 décadas y que ha atravesado diferentes gestiones gubernamentales.

Es oportuno subrayar que el Decreto Federal n.o 7 084/2010 instituyó el PNLD como un Programa de Estado (y no de gobierno). Ello es decisivo para la mejora y la consolidación de todo el proceso, el cual involucra desde la producción hasta la evaluación, selección y distribución de los libros. En este sentido, el PNLD consolidó un conjunto de lineamientos formulados a lo largo de más de 2 décadas, que se pueden resumir en los siguientes aspectos, entre otros: respeto al pluralismo de ideas y conceptos pedagógicos; respeto por la diversidad social, cultural y regional; respeto a la autonomía educativa de los establecimientos educativos; respeto por la libertad y apreciación de la tolerancia; y la garantía de igualdad, transparencia y publicidad en los procesos de evaluación, selección y adquisición de obras (Caimi, 2018).

Entre los lineamientos definidos en el ámbito del PNLD algunas reglas inciden directamente en la producción de los libros de texto. Así, entre las normas existe la definición de la cantidad de páginas que cada libro debe tener. De la misma manera, se determina que los libros deben contener pluralidades de ideas y percepciones historiográficas, didácticas y pedagógicas. De esta forma, es prohibido que los libros contengan alguna idea de discriminación o prejuicio a cualquier nacionalidad, etnia o grupo social. De la misma forma, las editoras están obligadas a producir una narrativa en defensa de la libertad y tolerancia. Además, deben promover la comprensión que estimule el aprecio hacia la diversidad religiosa, política y filosófica. Otro criterio importante es la garantía de la transparencia y publicidad en todas las etapas de producción, evaluación, adquisición y distribución.

Cualquier análisis de los libros de texto debe destinar especial atención a las relaciones de poder que condicionan, en cada experiencia de tiempo y lugar, las posibilidades de su producción. En este sentido, cabe destacar las reflexiones desarrolladas por Alain Chopin (2004) con respecto a la investigación sobre el 
libro de texto. Para él, "[...] el estudio sistemático del contexto legislativo y normativo, que condiciona no solo la existencia y estructura, sino también la producción del libro de texto es una condición preliminar indispensable para cualquier estudio sobre edición escolar". (Choppin, 2004, p. 561).

Esas reflexiones nos alertan sobre las precauciones que debemos tomar para evitar una crítica apresurada que se limita a señalar las lagunas de contenido en la narrativa escrita en los libros de texto. Para el contexto brasileño, señala Circe Fernandes (2009), estos han sido el principal foco de crítica dirigida a los libros, como si fuera posible tener un libro completo y perfecto. Es necesaria, por lo tanto, una comprensión del conjunto de relaciones político-sociales que construyen normas, reglas y condiciones que hacen con que un determinado libro sea considerado posible y otro inviable.

También, es importante mostrar la ubicación de la Amazonia brasileña para ampliar la comprensión de los lectores no nativos. El mapa siguiente (ver Figura 1) muestra la localización del área que forma la región amazónica, presentada en los libros de textos investigados en este artículo.

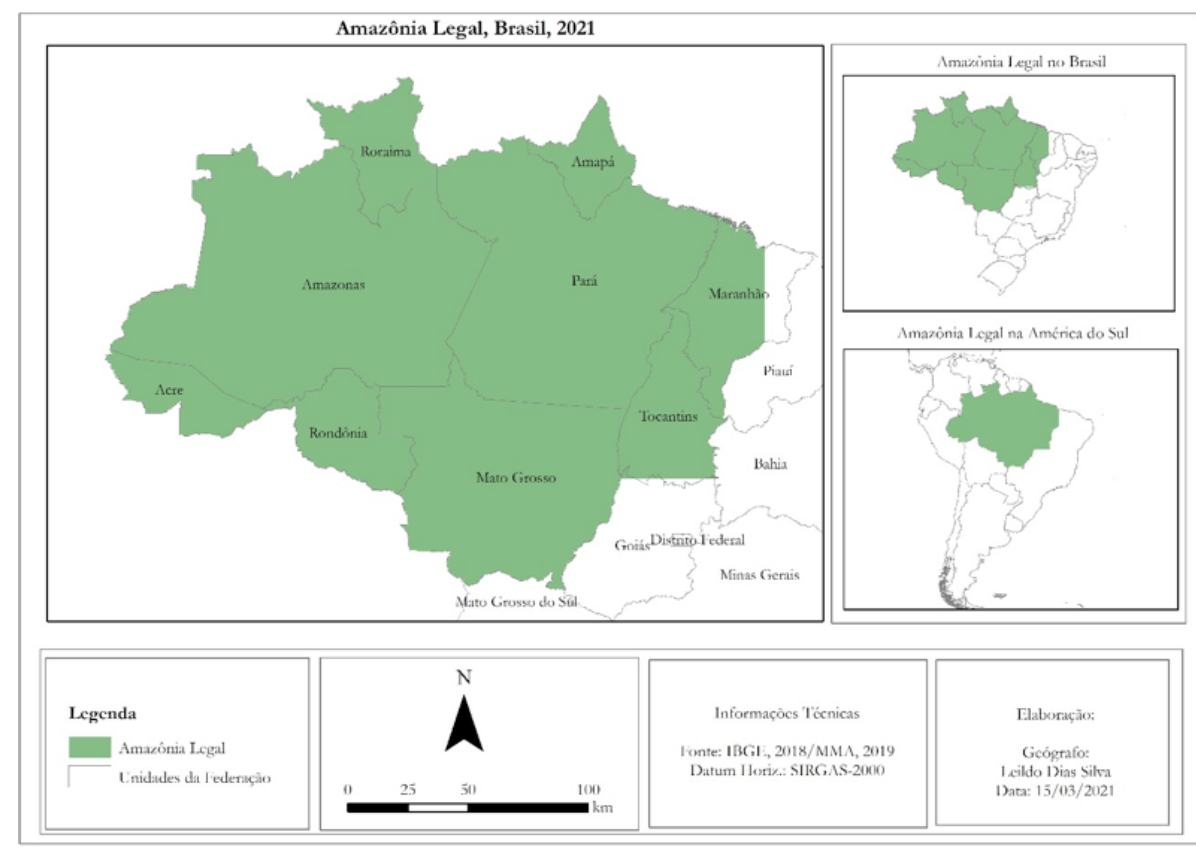

FIGURA 1

Mapa de localización de la Amazonia brasileña Fuente: Elaboración propia.

Según el Instituto Brasileiro de Geografia e Estatistica (IBGE), la Amazonia brasileña "[...] ]ocupa $5.015 .067,749 \mathrm{~km}^{2}$, correspondiente a cerca de 58,9\% del territorio brasileño $\left(8.510 .295,914 \mathrm{~km}^{2}\right)$ " (IBGE, 2020, s/p).

La Amazonia es analizada a partir de diferentes objetos y aportes teóricos y metodológicos. La ciencia histórica ha recibido variadas contribuciones a partir de su investigación y análisis desde diferentes temáticas. ${ }^{2}$ El crecimiento de la producción historiográfica sobre la región amazónica fue tema de reflexión del investigador Rafael Chambouleyron (2016). Él destacó la densidad cuantitativa y cualitativa de las investigaciones que tematizaron la Amazonia, especialmente, en lo que se refiere a las experiencias durante la ocupación de Portugal, en la llamada América portuguesa. ${ }^{3}$

El antropólogo Alfredo Wagner Berno de Almeida (2009) realiza una importante reflexión sobre el concepto de archivo -desde el debate propuesto por Michel Foucault- para problematizar algunos conceptos movilizados por diferentes áreas del conocimiento a la hora de intentar explicar y representar la Amazonia. Almeida (2009) es enfático al afirmar que la construcción y el mantenimiento de estos archivos también fueron utilizados para crear esquemas interpretativos simplistas, dualistas y naturalistas sobre la Amazonia. 
Así, en distintas épocas y desde distintos lugares de enunciación, la Amazonia se fue construyendo a través de explicaciones basadas en diferentes formaciones discursivas, especialmente las relacionadas con los biologismos, los geografismos y sus dualismos.

Para analizar cómo se representa la Amazonia en los libros de texto de Historia es igualmente importante comprender qué significa la representación. Para la problematización aquí desarrollada, utilizo las reflexiones promovidas por Roger Chartier (2011), para el cual la representación es aprehendida como un conjunto variado de elementos y prácticas capaces de mostrar algo que está ausente y que se constituye como una de las fuerzas productivas del mundo social. Como defiende el autor, "[...] no hay historia posible si no se articulan las representaciones de prácticas y las prácticas de representación”. (Chartier, 2011, p. 16). Su análisis llama la atención sobre la relación entre las fuentes documentales y las prácticas que representan, sin una relación complementaria y transparente entre esas dimensiones.

\section{CONTEXTUALIZAR EL TEMA: UNA MIRADA DESDE LA LITERATURA ESPECIALIZADA}

En Brasil, el libro de texto de Historia es un objeto popularmente conocido y reconocido por las comunidades escolares y académicas. En consecuencia, se ha constituido como objeto de investigación especializada y como herramienta de trabajo. Es un producto complejo, cuya definición no es fácil. Para ser fabricado necesita de muchos profesionales de variadas áreas de especialización. Ese instrumento ha sido debatido, analizado, reformulado, utilizado y abusado de diferentes formas y por diferentes profesionales durante mucho tiempo. Los profesores de educación primaria y secundaria utilizan el libro de texto como su principal (y, a veces, única) herramienta de trabajo, en la mayoría de las escuelas de Brasil. De igual manera, como objeto de investigación académica, también ha despertado el interés de muchos investigadores que lo han analizado desde diferentes enfoques temáticos.

En el contexto internacional, las reflexiones de Alan Choppin (2004) son referencias importantes entre los investigadores y muestran la fecundidad de la investigación sobre el tema. Él señaló la complejidad que involucran los libros de texto, ya que existe una pluralidad semántica para designarlos, lo que crea un desafío cuando los expertos intentan definir tal objeto. En ese sentido, el autor enfatizó que "[...] la primera dificultad se relaciona con la definición del objeto en sí, que se traduce muy bien en la diversidad de vocabulario y la inestabilidad de los usos léxicos" (Choppin, 2004, p. 549). Posteriormente, Choppin (2008) destacó que los libros de texto se pueden estudiar desde diferentes puntos de vista. Además, señaló que no hay evidencia histórica sobre los libros de texto y enfatizó en la necesidad de comprender en qué se diferencian los libros de texto de otros libros. Para el autor es importante comprender los diferentes usos que se les da a los libros de texto en diferentes momentos.

Tulio Ramírez $(2003 ; 2012)$ es otro investigador que ha contribuido significativamente a las reflexiones. De hecho, su labor ha demostrado el potencial de ese tema como objeto de estudio, que permite amplia variedad de enfoques, ya que "[...] su contenido, los conocimientos que privilegia, sus omisiones, los valores que transmite, su estructura, su producción y comercialización, el marco legal que lo regula, los criterios utilizados por los docentes para seleccionar unos sobre otros" (Ramírez, 2003, p. 273) son algunos de los temas que se pueden desarrollar a partir del análisis de los textos didácticos. Ramírez (2012) también destacó esa herramienta como un objeto de interés político, por medio del cual se construyen diferentes narrativas históricas. Inés Quintero (2015) también ha contribuido a esas reflexiones en el contexto de Venezuela y mostró las principales ausencias identificadas en el análisis de libros de texto elaborado por el gobierno venezolano.

Alejandro Tiana (1999) mostró la relevancia, los desafíos y los aportes que el análisis de libros de texto significa para el campo de la Educación y del currículo, esto a partir de la investigación desarrollada en el proyecto MANES. ${ }^{4}$ Desde España tenemos la contribución de Juan Carlos Bel y Juan Carlos Colomer 
(2018). Estos autores presentaron un análisis sobre los procedimientos teóricos y metodológicos, basados en el estudio de actividades e imágenes relacionadas con la complejidad cognitiva. El estudio muestra que los libros de texto implican un papel central en la cultura escolar en la región iberoamericana. Todavía centrándose en el estudio de las imágenes presentes en los libros de texto, Rafael Valls (1999) analizó la selección y usos de las imágenes presentes en los libros de texto de Historia, a partir del ejemplo español y destacó la transformación del uso de imágenes de la ilustración a los documentos.

Entender el uso de los libros de texto desde la perspectiva de docentes y estudiantes fue el foco de interés de la investigación realizada por el profesor Nicolás Martínez Valcárcel (2016) de la Universidad de Murcia, España. El autor demostró que la investigación sobre los usos de los libros por parte de estudiantes y profesores es limitada y resaltó la relevancia del análisis para comprender cómo ese material didáctico es apropiado a partir de la información insertada en las páginas. Además, destacó un amplio conjunto de símbolos, dibujos, rasgos, respuestas a cuestionarios y grifos dejados por los estudiantes en los libros, señalando sus preferencias y sus formas interpretativas.

Aún es oportuno destacar los análisis de Gabriel Cabrera Becerra (2010), al investigar el lugar que ocupa la Amazonia en los manuales didácticos de Colombia entre los años 1880 y 1940. Según su investigación, los libros de texto analizados construyen una representación superficial de la Amazonia, ya que sus contenidos siguen una tradición que no dialoga con un conjunto de conocimientos ya disponibles sobre la región. En sus palabras: "[...] con respecto a la Amazonia, los manuales escolares son una fuente limitada cuyos contenidos son superficiales" (Becerra, 2010, p. 102). En los libros analizados en Colombia, los planteamientos defendidos por Becerra sobre la Amazonia se acercan mucho a los identificados en los libros brasileños que sirven de base para las reflexiones de este artículo.

Respecto a la investigación, en Brasil, sobre el libro de texto, podemos decir que hay una amplia y consistente producción especializada. Decenas de investigadores de diferentes instituciones han contribuido a las reflexiones. En ese sentido, la investigación muestra que no existe desacuerdo en cuanto a la influencia que tienen los libros de texto en las actividades docentes de la Educación Básica. Es por medio de esa herramienta que gran parte del profesorado desarrolla sus actividades de enseñanza. Por lo tanto, como destaca Katia Abud (2007) la importancia que han adquirido los textos didácticos los convierte en los instrumentos más poderosos en la producción del currículo en la vida escolar cotidiana. En este sentido, el libro de texto es casi el único material de apoyo que el docente encuentra a su disposición y, por tanto, apoya en él la parte central de su trabajo (p. 115).

También, merecen atención las reflexiones de Sônia Miranda y Fabiana Almeida (2020), Flávia Caimi (2017 y 2018), Margarida Oliveira (2017), Sônia Miranda y Tânia Regina de Luca (2004) quienes analizan el libro de texto de Historia como producto de política pública vinculada al PNLD. Circe Fernandes (2009) tiene una vasta producción por medio de la cual analiza el libro de texto como un producto cultural complejo, destacando sus aspectos como herramienta de trabajo docente y objeto de disputas políticas, curriculares e ideológicas. Célia Regina Cassiano (2017) ha reflexionado y ampliado el debate sobre la relación entre los libros de texto y el mercado editorial. Helenice Rocha (2018 y 2017), a su vez, ha centrado sus esfuerzos en reflexiones sobre el libro de texto y la producción de narrativas. Kazumi Munakata (2012) analiza el proceso de producción de esos libros y algunos temas de investigación presentes en ellos. Erinaldo Cavalcanti (2016; 2018 ; 2019) también ha discutido sobre el proceso de producción de libros de texto y la forma cómo se estudia esa herramienta durante la formación inicial de profesores de Historia en Brasil.

\section{PROCEDIMIENTOS METODOLÓGICOS}

Para la construcción de este artículo se ha procedido con el análisis cuantitativo y cualitativo de los documentos movilizados. La primera etapa comenzó con la selección de los libros. Para ello, seleccioné las 10 colecciones aprobadas en el PNLD 2018, las cuales fueron entregadas por las propias editoras en la escuela 
donde desarrollamos el proyecto de investigación. ${ }^{5}$ Luego, analicé las colecciones que hacían referencia a la Amazonia e identifiqué los libros (y los respectivos grados) en que se encontró la información procurada. Enseguida, pasé los textos que mencionaban la Amazonia a un documento digital en Microsoft Word y preparé tablas, así como gráficos basados en la información listada. A partir del conjunto de información catalogado, procedí a realizar el análisis cualitativo. A la vez, reflexionaba sobre el lugar que ocupa la Amazonia en el conjunto de los referidos libros y problematizaba qué narrativas estaban asociadas con la región.

\section{ANÁLISIS DE DATOS: UNA MIRADA DESDE LOS LIBROS DE TEXTO}

Las colecciones analizadas fueron las siguientes: Araribá Mais - História (Editora Moderna); Estudar História: das origens à era digital (Editora Moderna); História, escola e democracia (Editora Moderna); História, Sociedade e Cidadania (Editora FTD); Inspire (Editora FTD); História.doc (Editora Saraiva); Historiar (Editora Saraiva); Teláris (Editora Ática); Vontade de Saber (Editora Quinteto) e História: Geração Alfa (Editora SM Educação). Cada colección consta de 4 libros destinados a los últimos años de la Educación Básica (del $6^{\circ}$ hasta el $9^{\circ}$ grado).

La catalogación de los datos mostró que ninguna de las 10 colecciones poseía una unidad de estudio, o bien un capítulo específico sobre la Amazonia. Todavía, 7 colecciones hacen algún tipo de mención a la Amazonia y 3 -Araribá Mais-História (Ed. Moderna); Historiar (Ed. Saraiva) y Teláris (Ed. Ática)- no hacen ninguna referencia al tema.

Es importante explicar que el libro de texto de Historia está compuesto por diferentes componentes textuales y pre-textuales, además de los elementos que conforman la maquetación gráfica (incluyendo sesiones y recuadros específicos) y de mapas, tablas, cuadros e imágenes de diversos tipos y formatos. En general, los elementos textuales se dividen en dos categorías: texto principal y textos complementarios. En su amplia mayoría, los complementarios se incluyen en secciones específicas, también llamadas recuadros. Para reflexionar sobre este artículo, el análisis se ha centrado en el texto principal. Así, resultó interesante conocer qué narrativas se construyeron sobre la Amazonia en el texto principal presente en los libros de texto. En cuanto a la estructura, los libros están constituidos por unidades temáticas, compuestas por capitulos. Estos se dividen en los temas principales y sus subtemas.

La Amazonia no reemplaza temas considerados clásicos y dignos de una unidad o, incluso, de un capítulo. De este modo, entre los 40 libros analizados, ningún capítulo está dedicado específicamente a la Amazonia y, cuando los libros mencionan a la Amazonia, esa región aparece solo como un subtema dentro de un capítulo con otro tema general.

También, notamos que hay una mayor concentración de narrativas que mencionan a la Amazonia en libros para el 6..$^{\circ}$ grado. Así, de las 7 colecciones que hacen referencia a la Amazonia, 5 están incluidas en el libro destinado al $60^{\circ}$ grado. Ese dato ya nos permite identificar en qué temporalidad las narrativas representan la Amazonia. Los libros del 6..$^{\circ}$ grado, de diferentes formas, abordan los contenidos que, en términos aproximados, datan de la aparición del hombre hasta el siglo XV de la era cristiana. La Tabla 1 representa los temas que están relacionados con la Amazonia. 
TABLA 1

Identificación de los temas que representan la Amazonia

\begin{tabular}{|c|c|c|}
\hline \multicolumn{3}{|c|}{ Relación editora, tema Amazonia y grado } \\
\hline Editorial & Temáticas sobre la Amazonia & Grado/año \\
\hline $\begin{array}{c}\text { Moderna (Estudar História: } \\
\text { das origens à era digital) }\end{array}$ & $\begin{array}{l}\text { Cultivos agrícolas de la } \\
\text { Amazonia }\end{array}$ & $6 .^{\circ}$ \\
\hline $\begin{array}{c}\text { Moderna (História, escola e } \\
\text { democracia) }\end{array}$ & La Amazonia & $7 .^{\circ}$ \\
\hline $\begin{array}{c}\text { Moderna (História, escola e } \\
\text { democracia) }\end{array}$ & $\begin{array}{l}\text { La Amazonia y los pueblos } \\
\text { indígenas }\end{array}$ & $8 .^{\circ}$ \\
\hline $\begin{array}{c}\text { FTD (História, Sociedade e } \\
\text { Cidadania) }\end{array}$ & Agricultores en el Amazonas & $6 .^{\circ}$ \\
\hline FTD (Inspire) & Sociedades amazónicas & $6 .^{\circ}$ \\
\hline FTD (Inspire) & Colonización del Norte & $7 .^{\circ}$ \\
\hline Saraiva (História.doc) & Caucho en el Amazonas & $9 .^{\circ}$ \\
\hline $\begin{array}{c}\text { Quinteto (Vontade de } \\
\text { Saber) }\end{array}$ & Marajoara y Tapajoara & $6 .^{\circ}$ \\
\hline $\begin{array}{c}\text { SM Educação (História: } \\
\text { Geração Alfa) }\end{array}$ & Grandes pueblos amazónicos & $6 .^{\circ}$ \\
\hline
\end{tabular}

Fuente: Elaboración propia.

De los 40 libros, solo 9 mencionan la región amazónica. Cada una de las colecciones -Historia, escuela $y$ democracia e Inspirar-presentan dos libros que mencionan la Amazonia. Tales narrativas ocupan, en promedio, 1 o 2 párrafos sobre la Amazonia. En dichos párrafos la región se presenta de forma genérica y como un área homogénea. Las narrativas se limitan a mencionar que hay rastros de presencia humana en la región que datan del periodo entre dos mil (Editorial SM Educação - História: Geração Alfa) y once mil años (Editorial Moderna - Estudar a História: das origens à era digital).

Una vez que la Amazonia no es un asunto específico de una unidad o un capítulo, esta no aparece vinculada a otros temas. Las narrativas sobre la región están asociadas a dos grandes temas: por un lado, la aparición del hombre en América y, por otro, el proceso de colonización portuguesa en Brasil. Hay una excepción, que es la narrativa de la colección Editorial Saraiva (História.doc) para el libro de 9. grado, en el que la Amazonia es narrada juntamente con el proceso de industrialización y comercialización del caucho, entre fines del siglo XIX y el principio del siglo XX. En el conjunto de libros se identificaron 5 menciones que asocian la Amazonia con la aparición del hombre, 3 vinculadas al proceso de colonización y una a lo que podemos llamar industrialización vinculada a la extracción de caucho.

\section{CÓMO LOS LIBROS REPRESENTAN LA AMAZONIA}

De la información contenida en los libros se desprende que la Amazonia es representada a través de una narrativa vinculada a una experiencia de un tiempo lejano. La Amazonia es, por lo tanto, un tema lejano en el tiempo, asociado con la aparición del hombre o con los acontecimientos del llamado período colonial. En 
otras palabras, la poca información que ofrecen los libros está ligada a los relatos de la invasión portuguesa, denominada convencionalmente colonización o conquista. A excepción de la Editorial Saraiva (História.doc) sobre el caucho, que está ligada a la experiencia del período republicano, la Amazonia desaparece de las narrativas didácticas. En esos términos, es como si la historia de la Amazonia se restringiera al período de la aparición del hombre en América, o bien al de la colonización portuguesa.

A través de las narrativas didácticas, la historia de la Amazonia se sigue presentando como un lugar exótico, ubicado en un pasado lejano y de personas sin nombre. Ninguna de las narrativas de los 9 libros trae el nombre de los hombres y mujeres que vivieron y viven en la región. Las poblaciones permanecen innombradas en los libros de texto. Se presentan en categorías como nativos, indigenas y agricultores; expresiones que dicen poco o casi nada. Una gramática que contribuye a borrar sujetos y silenciar sus vivencias. Una semántica que invisibiliza a las personas (porque no se presentan por nombre) y las representa (cuando las representa) solo como datos estadísticos de una época lejana.

Las narrativas sobre personas sin nombre (que son casi equivalentes a personas sin historia) todavía se identifican cuando los libros de texto hacen uso de la investigación académica para reforzar y legitimar su argumento. En este sentido, veamos cómo el libro de $6 .^{\circ}$ grado (FTD Editorial - História, Sociedade e Cidadania) se refiere a la Amazonia:

Según la arqueóloga Anna Roosevelt, la gente de la región amazónica comenzó a practicar la agricultura hace unos 7 mil años. Desarrollaron sus propios cultivos, como plantas medicinales y tintes; pero el descubrimiento más importante de estos grupos fue el cultivo de la mandioca, raíz de alto valor nutricional con algunas variedades venenosas. Los agricultores de la Amazonia descubrieron que al rallar, presionar y tostar estas especies de mandioca podían extraer el veneno que contenían. Produjeron alimentos como harina, beiju ${ }^{6}$ y tapioca (FDT, Editorial, 2020, p. 62).

Este párrafo, transcrito íntegramente, es la narrativa del texto principal que conforma el subtema Agricultores de la Amazonia, que se encuentra en el cuarto capítulo del libro del 6. Grado. El referido capítulo, titulado Primeros habitantes de América, consta de 13 páginas, ubicadas entre las páginas 52 y 65 . Como puede verse, la Amazonia se narra como un bloque homogéneo de personas igualmente homogéneas en el que todos viven con los mismos hábitos y prácticas culturales. Tales narrativas didácticas contribuyen a silenciar las historias e invisibilizar a las personas que están representadas en categorías simplificadoras. En la misma página del párrafo mencionado, hay la fotografía de una joven indígena rallando mandioca. La identificación que aparece en el pie de foto la representa únicamente como Moça Kalapaio ralando mandioca no Parque Indigena do Xingu (MT), 2011 (FDT, Editorial, 6. ${ }^{\circ}$ Grado, 2020, p. 62). Es decir, ni siquiera frente a una fotografía con la imagen de una persona se dan nombres a los sujetos narrados.

No solo los sujetos mencionados en las narrativas sobre la Amazonia carecen de nombres, identidades y especificidades. En el bloque de narrativas, que vincula la temática amazónica con el período colonial, los sujetos -que permanecen sin nombre- no aparecen como los actores responsables de las historias allí reportadas. Veamos cómo una de las colecciones (7.o grado) representa al Amazonas desde este ángulo:

En la Amazonia, las misiones jesuitas también fueron importantes en la ocupación del territorio por parte de Portugal, sirviendo como agentes de pacificación. Sus misiones, así como las de los franciscanos, carmelitas y capuchinos, allanaron el camino para la entrada de luso-brasileños. Belém, fundada en 1616, fue el punto de partida de los hombres que, remontando el río Amazonas y sus afluentes, exploraban la región en busca de indígenas y plantas nativas para vender a Europa: cacao, canela, pimienta, castaña, etc. Con ello, ampliaron los territorios de los portugueses, que, a principios del siglo XVIII, ya ocupaban los puntos estratégicos de la inmensa cuenca amazónica (Moderna Editorial, 2020, p. 15).

Esta es la narrativa didáctica que forma parte del texto principal del libro de $7 .{ }^{\circ}$ grado de la Editorial Moderna. Es parte del capítulo 7, titulado La conquista de la América colonial portuguesa. Ese capítulo se compone de un total de 17 páginas y consta de temas y subtemas divididos en pequeñas sesiones temáticas, entre ellas, la Amazonia. 
La Amazonia, como podemos ver, es narrada a partir de la historia de la ocupación de los portugueses en la región. Específicamente, la narrativa didáctica presenta la historia como resultado del desarrollo de esa ocupación. En otras palabras, la región pasa a formar parte de la historia como una extensión del proyecto de colonización. Dicho proyecto está representado, sobre todo, por las acciones impulsadas por la política de catequesis, especialmente las vinculadas a las misiones jesuitas.

El surgimiento de la ciudad de Belém (capital de la actual provincia de Pará), también se narra como una construcción exclusiva de los hombres responsables de esa historia. Aparece, por lo tanto, como un trabajo específico de la iniciativa de hombres, representantes de la nacionalidad portuguesa. De esa forma, habría sido obra de quienes recorrieron las rutas fluviales para incrementar las relaciones comerciales y ampliar sus dominios. Tales iniciativas describen el gobierno portugués como sujeto responsable, una representación que sitúa a la Amazonia como resultado de los intereses de la corona portuguesa, que ya había ocupado los principales puntos estratégicos de la cuenca amazónica.

Los demás libros que insertan alguna información sobre la región en sus páginas no escapan a esa representación. Encontramos el mismo procedimiento narrativo en la colección Inspire (en el libro de $6 .^{\circ}$ grado), de la Editorial FTD:

Desde los primeros tiempos de la colonia, la región amazónica ha recibido a comerciantes franceses e ingleses interesados en el palo de Brasil. Además, buscaron otros productos tropicales de gran valor en Europa, como aves de plumaje de colores (loros, guacamayos), pieles de animales, hierbas aromáticas y plantas medicinales. A cambio de estos productos, entregaban a los indígenas hachas de metal, cuchillos y otros utensilios (Seriacopi y Azevedo, FDT Editorial, 2020, p. 195).

La Amazonia se presenta a partir de los mismos hitos temáticos de la historia colonial tradicional y clásica. Lugar exótico que aporta productos relacionados con la fauna y la flora de Europa. La misma estructura narrativa se moviliza al narrar el proceso de intensificación de ocupación (invasión) portuguesa en la región amazónica:

fue solo en la época de la Unión Ibérica que los gobernadores de Portugal y España se esforzaron por conquistar la actual región norte de Brasil. La ocupación de la región fue causada, en gran parte, por la invasión francesa de Maranhão, en 1612. Se enviaron tropas para expulsar a los franceses de la región en 1615 por temor a una invasión y la toma de esas tierras por rivales europeos. Al mismo tiempo, se creó una administración exclusivamente para la colonización de la actual región Norte (Seriacopi y Azevedo, 2018, 6. ${ }^{\circ}$ grado, p. 195).

El protagonista de la acción narrada es la monarquía portuguesa, ahora aliada con la monarquía española. Ambas actúan unidas, en ese momento, movilizadas por los intereses del proyecto de colonización. En otras palabras, la ocupación del norte de Brasil (en el llamado período colonial), hoy día aparece como consecuencia de los sujetos que representan Portugal y España. La narrativa didáctica sigue presentando la región por medio de estos lentes, cuando informa que los portugueses decidieron actuar y ocupar efectivamente la región norte para evitar que los franceses avanzaran (en la ocasión de la invasión del actual estado de Maranhão).

$\mathrm{Al}$ analizar los fragmentos textuales que tratan de la Amazonia, también se observa cómo el contenido de las narrativas didácticas sobre los pueblos indígenas en la Amazonia no difiere de la representación que comúnmente se elabora sobre la corona portuguesa y los indígenas que vivían en la costa al inicio de la colonización. Si quitamos las expresiones que identifican textualmente a la Amazonia, la narrativa también sirve para relatar -de manera genérica, ciertamente- cualquier experiencia desarrollada durante ese período, entre los colonizadores y los pueblos indígenas que vivieron en ese espacio, luego llamado Brasil.

Otro elemento también llama la atención por su ausencia. De los 9 libros, solo 1 presenta un mapa sobre la ubicación geográfica de la Amazonia. Es decir, por descuido o cualquier otro motivo, solo el Editorial FDT (Inspire) inserta un mapa con la ubicación de la Amazonia y su extensión territorial. No podemos olvidar que son narrativas producidas para niños del 6. ${ }^{\circ}$ grado con una edad media entre los 10 y los 12 años. Quizás, para esos estudiantes, no sea tan obvio dónde se encuentra exactamente la Amazonia y cuál su tamaño de área geográfica. 
Las narrativas sobre la Amazonia -ya sean relacionadas con el surgimiento del hombre en América, o bien asociadas al proceso de colonización portuguesa en el espacio ahora llamado Brasil- esconden la participación de hombres y mujeres que vivieron en esa región. Esa invisibilidad no se da solo por las categorías utilizadas para mencionar las innumerables etnias que vivían en la Amazonia, como ya se demostró. También, se debe a la forma con que se presentan las historias. Es decir, en las narrativas sobre la Amazonia, independientemente del tema abordado y del tamaño de la narrativa textual, el responsable de las acciones desencadenadas es el hombre de origen europeo o representante del proyecto político de la colonización portuguesa.

Las personas que vivieron en la vasta región amazónica y actuaron de diferentes formas durante el proceso de colonización en la llamada región norte son ignoradas de las narrativas didácticas. Los que aparecen como campesinos, nativos o habitantes, cuando la narrativa se refiere al tema de la aparición del hombre, comienzan a agruparse en la categoría de indígenas, sin especificar la diversidad de sus etnias. Además de la homogeneización presentada en la narrativa sobre los pueblos del Amazonas, esos se insertan como sujetos pasivos en los relatos.

Si los sujetos que vivieron en la Amazonia están homogeneizados, representados en conceptos que niegan sus singularidades, las mujeres son aún más silenciadas en el texto principal de los libros analizados. No hay ninguna referencia a las mujeres en la narrativa textual. Ellas siquiera aparecen en la concordancia gramatical, porque la narrativa se construye con la figura masculina como sujeto de referencia. En las oraciones gramaticales, los sujetos son los indígenas, los agricultores, los nativos.

Los análisis realizados permiten percibir algunas similitudes con la investigación desarrollada por Gabriel Becerra (2010). En los libros de texto brasileños, así como en los colombianos, las editoras desconocen las principales discusiones disponibles por áreas especializadas del conocimiento. Para ese autor, los libros didácticos colombianos de Educación Básica no conocen o no privilegian a la Amazonia y sus contenidos ignoran un conjunto de conocimientos disponibles sobre la región.

Otra similitud identificada se refiere al trato de los pueblos indígenas. En los libros analizados en este artículo, las poblaciones nativas aparecen estereotipadas en narrativas didácticas. Esa forma de representación no es muy diferente de la identificada por Becerra (2010). Según este mismo autor, “[...] en los manuales de estudio más elaborados sobre los pueblos indígenas que ocuparon la Amazonia y un nuevo estudio solo ocupó el período comprendido entre 1880 y 1940" (p. 104).

Identificar estos temas no significa argumentar que las narrativas de los libros de texto tendrían que dar cuenta de toda la pluralidad de historias sobre las diversas etnias que habitaban la región conocida como Amazonia, no. No sería posible construir una narrativa capaz de representar toda la complejidad de experiencias tan múltiples y heterogéneas. El análisis se dirige a otro camino: reflejar cómo las narrativas de los libros de texto representan la Amazonia. En este sentido, se pretende ampliar el debate sobre qué temas se seleccionan en los libros utilizados por la mayoría de los alumnos de las escuelas públicas. De la misma manera, se busca cuestionar ¿qué promueve la selección de un tema para que se convierta en el contenido de un libro de texto?; ¿por qué algunos temas se elevan a la escalera de la fama de los contenidos de los libros de texto?; ¿por qué algunos son abordados en unidades temáticas y otros en capítulos?; ¿ por qué algunos aparecen solo como un pequeño tema dentro de un capítulo o incluso como un subtema?

Esos análisis deben estar presentes cuando reflejamos qué narrativas se construyen en los libros de texto de Historia. Además, hace falta entender que las narrativas presentes en los libros de texto no son construcciones ajenas. Por el contrario, son productos culturales resultado de un conjunto de relaciones que involucran muchos factores. A su vez dichos factores se relacionan relacionados con diferentes instituciones y lugares de legitimación del conocimiento y poder. Así, de nada sirve analizar la representación de las narrativas en los libros didácticos sobre la Amazonia si se considera que el problema ya está solucionado al señalar las fallas. 


\section{CONCLUSIONES}

A partir de las reflexiones aquí presentadas, es posible percibir la complejidad del proceso de producción del libro de texto de Historia. También es evidente la complejidad de la producción de la narrativa didáctica como constructora de determinadas representaciones de los relatos narrados. Sobre las narrativas didácticas que representan la Amazonia, en los libros de Historia (aprobados en el PNLD 2018 y discutidos aquí), los análisis muestran el reducido lugar que la región, como tema de estudio, ocupa en el conjunto de contenidos presentes en los últimos años de la Educación Básica.

La Amazonia, en las narrativas didácticas, aparece como un lugar sin gente, o con gente sin historia, sin nombre, sin identidad, ya que todas las personas están narradas de forma generalizada y representadas en narrativas homogeneizadoras. Con todo, no podemos atribuir a los libros de texto la responsabilidad exclusiva de las representaciones que allí se encuentran. Sí, hay responsabilidades para todos los actores sociales que participan en la producción de esos libros. Esa producción involucra muchas variables y diferentes intereses políticos, intelectuales y comerciales. Sin embargo, no debemos olvidar que es una herramienta de trabajo para miles de docentes y un objeto de estudio para millones de alumnos que estudiarán y aprenderán en el espacio escolar donde los libros texto son las principales referencias.

\section{REFERENCIAS}

Abud, K. M. (2017). A história de cada dia: saber escolar e saber acadêmico na sala de aula. En: A.M. Monteiro, A. M. Gasparello, y M. S. Magalhães (Org.) Ensino de história: sujeitos, saberes e práticas (pp. 107-119). Mauad X.

Almeida, A. W. (2008). Antropologiados Archivos da Amazônia (2da ed). Casa 8 Fundação Universidade do Amazonas.

Alves-Melo, P. M. (2016). Histoires, identités et frontières: Indiens et Africains dans l'Amazonie coloniale. Caravelle, (107), 45-55. https://doi.org/10.4000/caravelle.2076

Bel, J. C. y Colomer, J. C. (2018). Teoría y metodología de investigación sobre libros de textos: análisis didáctico de las actividades, las imágenes y los recursos digitales en la enseñanza de las ciencias sociales. Revista Brasileira de Educação, 23, 1-23. https://doi.org/10.1590/s1413-24782018230082

Boulos, A. (2018). História, Sociedade e Cidadania. FTD Educação.

Braick, P. y Barreto, A. (2018). Estudar História: das origens à era digital. Editora Moderna.

Cabrera, G. (2010). Los manuales escolares colombianos y la Amazonia, 1880-1940. Historia y sociedad, (18), 83-106. Recuperado de https://revistas.unal.edu.co/index.php/hisysoc/article/view/23585

Caimi, F. (2017). O livro didático de história e suas imperfeições: repercussões do PNLD após 20 anos. En: H. Rocha, L. Reznik, y M.S. Magalhães (Coord.).Livros Didáticos De História - entre políticas e narrativas (pp. 33-54). FGV Editora.

Caimi, F. E. (2018). Sob nova direção: o PNLD e seus desafios frente aos contextos político-educativos emergentes. Revista História Hoje, 7(14), 21-40. https://doi.org/10.20949/rhhj.v7i14

Campos, F., Claro, R. y Dolhnikoft, M. (2020). História, escola e democracia. Editora Moderna.

Cassiano, C. (2017). Política e economia de mercado do livro didático no século XXI: globalização, tecnologia e capitalismo na educação básica nacional. En: H. Rocha, L. Reznik, y M.S. Magalhães (Org.). Livros Didáticos De História - entre politicas e narrativas (pp. 83-100). FGV Editora.

Cavalcanti, E. (2016). Livro didático: produção, possibilidades e desafios para o ensino de História. Revista História Hoje, 5(9), 262-284. https://doi.org/10.20949/rhhj.v5i9.219

Cavalcanti, E. (2018). História, livro didático e formação docente: produção, limites e possibilidades. Antiteses, 11 (22), 516-532. http://dx.doi.org/10.5433/1984-3356.2018v11n22p516

Cavalcanti, E. (2019). Ensino de História, livro didático e formação docente de professores de História no Brasil. Enseñanza de las Ciencias Sociales, (18), 49-61. http://dx.doi.org/10.1344/ECCSS2019.18.4 
Cavalcanti, E. (2021). O lugar da Amazônia nos livros didáticos de História no Brasil: sobre história, narrativa e ensino. Revista de Estudios Brasileños, 8(16), 187-202. https://revistas.usal.es/index.php/2386-4540/article/view/reb2 021816187202

Chambouleyron, R. (2016). Território e ocupação na Amazônia joanina (1707-1750): percursos historiográficos do século XXI. Revista Maracanan, (16), 214-220. https://doi.org/10.12957/revmar.2016.24698

Chartier, R. (2011). Defesa e ilustração da noção de representação. Fronteiras, Dourados, 13(24), 15-29. https://ojs.u fgd.edu.br/index.php/FRONTEIRAS/article/view/1598

Choppin, A. (2004). História dos livros e das edições didáticas: sobre o estado da arte. Educação e Pesquisa, 30(3), 549-566. https://doi.org/10.1590/S1517-97022004000300012

Choppin, A. (2008). O manual escolar: uma falsa evidência histórica. Históriada Educação, 13(27), 9-75. https://see r.ufrgs.br/asphe/article/view/29026

Cotrim, G. y Rodrigues, J. (2018). Historiar. Editora Saraiva.

Decreto n. ${ }^{\circ}$ 7084. (2010). http://www.planalto.gov.br/ccivil_03/_Ato2007-2010/2010/Decreto/D7084.htm

Dias, A. M., Krinberg, K. y Pellegrini, M. (2018). Vontade de Saber. Quinteto.

Educação, SM. (2018). História - Geração Alfa. São Paulo.

Fernandes, C. M. (2009). Ensino de História: fundamentos e métodos (2da ed.). Cortez Editora.

Figueiredo, A. M. (2013). Flechas com ponta de aço: imagem, política e historiografia indigenista na Amazônia nas primeiras décadas do século XX. Muiraquitã: Revista De Letras E Humanidades, 2(1), 47-71. https://doi.org/ 10.29327/210932.2.1-3

Instituto Brasileiro de Geografía e Estatística-IBGE. (2020). [IBGE atualiza Mapa da Amazônia Legal]. Recuperado el 2 de marzo de 2021. https://agenciadenoticias.ibge.gov.br/agencia-sala-de-imprensa/2013-agencia-de-notici as/releases/28089-ibge-atualiza-mapa-da-amazonia-legal

Miranda, S. R. y Almeida, F. R. (2020). Passado, presente e futuro dos livros didáticos de História frente a uma BNCC sem futuro. Escritas do Tempo, 2(5), 10-38. https://doi.org/10.47694/issn.2674-7758.v2.i5.2020.1038

Miranda, S. R. y Luca, T. R. (2004). O livro didático de história hoje: um panorama a partir do PNLD. Revista Brasileira de História, 24(48), 123-144. http://dx.doi.org/10.1590/S0102-01882004000200006

Moderna. (2018). Araribá Mais - História. Editora Moderna.

Munakata, K. (2012). O livro didático: alguns temas de pesquisa. Revista Brasileira de História da Educação, 12(3), 179-197. http://dx.doi.org/10.4322/rbhe.2013.008

Oliveira, M. M. (2017). Uma profissional de história em gestão de políticas públicas: como a memória construiu minha experiência no PNLD de 2004 a 2015. En: H. Rocha, L. Reznik, y M.S. Magalhães (Org.). Livros didáticos de história: entre politicas e narrativas (pp. 55-66). FVG Editora.

Pereira, A. R. (2015). Do posseiro ao sem-terra: A luta pela terra no sul e sudeste do Pará. Editora UFPE.

Quintero, I. (2015). Enseñar Historia en Venezuela: carencias tensiones y conflictos. Caravelle, (104), 71-86. https: //doi.org/10.4000/caravelle.1576

Ramírez, T. (2003). El texto escolar: una línea de investigación en Educación. Revista de Pedagogía, 24(70), 273-292. http://ve.scielo.org/scielo.php?script=sci_arttext\&pid=S0798-97922003000200003

Ramírez, T. (2012). El texto escolar como arma política. Venezuela y su gente: ciencias sociales, $6^{\circ} \mathrm{Grado}$. Investigación y Posgrado, 27(1), 163-194. http://ve.scielo.org/pdf/ip/v27n1/art07.pdf

Rocha, H. (2017). Livro didático de história em análise: a força da tradição e transformações possíveis. En: H. Rocha, L. Reznik, y M.S. Magalhães (Org.).Livros didáticos de história: entrepoliticas e narrativas (pp. 11-30). FVG Editora.

Rocha, H. (2018). Desafios presentes nos livros didáticos de História: narrar o que ainda está acontecendo. Revista História Hoje, 7(14), 86-106. https://doi.org/10.20949/rhhj.v7i14.466

Seriacopi, R. y Azevedo, G. (2018). Inspire História (1 ra ed.). FTD.

Théry, H. (2005). Situações da Amazônia no Brasil e no continente. Estudos Avançados, 19(53), 37-49. https://doi.o rg/10.1590/S0103-40142005000100003 
Erinaldo Cavalcanti. El lugar de la Amazonia en los libros de texto de historia en Brasil: Sobre h...

Tiana, A. (1999). La investigación histórica sobre los manuales escolares en España: el Proyecto Manes. Clio \& Asociados. La Historia enseñada, 1(4), 121-130. https://doi.org/10.14409/cya.v1i4.1548

Vaifas, R., Ferreira, J., Faria, S. C. y Calainho, D. B. (2018). História.doc. Editora Saraiva.

Valcárcel, N. M. (2016). El uso de libro de texto de historia de España en Bachillerato: entre el aula y la casa. Hist. Educ, 20(50), 69-93. https://dx.doi.org/10.1590/2236-3459/62453

Valls, R. (1999). Sobre la selección y usos de las imágenes de los manuales escolares de Historia: un ejemplo español (1900-1998). Clio\& Asociados. La Historia enseñada, 1(4), 77-100. https://doi.org/10.14409/cya.v1i4.1547

Vicentino, C. y Vicentino, J. B. (2018). Teláris História. Editora Ática.

\section{Notas}

1 Específicamente, la investigación desarrollada en iTemnpo, que forma parte del proyecto en CEINCE, se inserta en el eje temático Poder y control social. Aquí se analiza cómo se narran y representan las experiencias democráticas y dictatoriales en el ámbito iberoamericano. Debo aclarar que, en 2021, se publicó una parte de la investigación que analiza el lugar que ocupa la Amazonía en los libros de texto y su relación con la enseñanza de la Historia.

2 El investigador Hervé Théry (2005) mostró cómo aún prevalecen algunas interpretaciones dicotómicas y dualistas sobre la Amazonia. A pesar de ocupar la mayor porción territorial de Brasil, ese investigador muestra cómo la Amazonia todavía tiene tasas preocupantes sobre su PIB, su población urbana. Para él, el indicador que supera a los demás, en comparación con otras regiones de Brasil, es el resultado de las tasas de violencia. También, según él, la Amazonia supera la cuota nacional en cuanto al número de muertos por conflictos agrarios. En este sentido, la reflexión desarrollada por el investigador Airton dos Reis Pereira (2015) al abordar la lucha por la tierra en el sur y sureste de Pará es de lectura obligatoria.

3 Aldrin de Moura Figueiredo (2013), a su vez, destaca las disputas en el debate sobre las políticas indígenas en y sobre la Amazonia, centrándose en la actuación de los intelectuales y los enfrentamientos que involucran la defensa de un determinado proyecto institucional. Patrícia Alves-Melo Sampaio (2016), también ha contribuido al debate. Ella destaca aspectos de la dinámica del mundo del trabajo en la Amazonia colonial con un enfoque en las experiencias históricas de las poblaciones nativas, especialmente las de origen africano e indígena.

4 MANES es un Centro de Investigación interuniversitario dedicado al estudio histórico de los manuales escolares de España, Portugal y América Latina, especialmente en los siglos XIX y XX.

5 Durante 2019 desarrollamos el proyecto PIBID en la escuela pública O Pequeno Principe, ubicada en la ciudad de Marabá (PA, Brasil). Cada 3 años, las editoras distribuyen copias aprobadas en el último PNLD para que los docentes analicen y elijan las obras con las que desean trabajar en los próximos años.

6 Una comida típica de la culinaria brasileña (presente en la Amazonia) hecha de mandioca. 